\title{
Evaluation of serum levels of irisin and nesfatin-1 in patients with migraine without aura
}

\author{
Turan Akdag', (1) Faruk Omer Odabas²
}

'Department of Plant and Animal Production, Meram Vocational School, Necmettin Erbakan University, Konya, Turkey

${ }^{2}$ Department of Neurology, Konya Education and Research Hospital, University of Health Science Konya, Turkey

\begin{abstract}
Objectives: Migraine is a chronic neurological disorder. A number of cytokines have been linked to the pathogenesis of migraine. This is a preliminary assessment to determine and analyze the serum levels of irisin and nesfatin-1 in patients with migraine without aura.

Methods: A total of 80 participants, 40 patients who had been diagnosed with migraine without aura (10 men, 30 women) and 40 healthy controls ( 10 men, 30 women), were included in the study. The serum irisin and nesfatin- 1 parameters were investigated using blood samples drawn from the patient and control groups.

Results: The mean serum irisin level was $16.87 \pm 14.66 \mathrm{ng} / \mathrm{mL}$ in the migraine group and $17.33 \pm 17.18 \mathrm{ng} / \mathrm{mL}$ in the healthy controls. No significant $p$ value was determined $(p=0.470)$, but the level was slightly lower in the migraine group. The mean nesfatin- 1 level was $4.71 \pm 5.96 \mathrm{mmol} / \mathrm{L}$ in the migraine group and $4.13 \pm 5.41 \mathrm{mmol} / \mathrm{L}$ in the healthy controls $(p=0.19)$, again revealing a small but statistically insignificant difference. In addition, there was no statistically significant difference according to age group, visual analog scale score for pain, body mass index, or length of disease duration.

Conclusion: Although no statistically significant differences were observed, the present study is believed to be the first to provide insight on the serum levels of irisin and nesfatin-1 in migraine without aura patients.

Keywords: Headache, irisin, migraine, nesfatin-1
\end{abstract}

$\mathrm{M}$ graine is defined as a neurovascular disorder with neurogenic inflammation and contractile dysfunction of the cranial blood vessels [1]. It is a headache disorder that is accompanied by different combinations of neurological and autonomic disorders [2]. Clinically, there are 2 classic types of migraine: with and without aura. Migraine without aura is the most frequent form of primary headaches $(60-80 \%$ of all migraines). The clinical symptoms of migraine without aura include pulsating pain, pain on at least one side of the head, sensitivity to sound and light, and vomiting and/or nausea [3]. Migraine attacks decrease quality of life (QoL), and may also cause a fiscal burden for individuals and organizations due to medical expenses. Inadequate treatment can lead to more frequent migraine attacks and more disruption for the sufferers.
According to the World Health Organization (WHO), migraine is a cause of labor loss as a result of the headache pain and distress (ranking $19^{\text {th }}$ for men and $12^{\text {th }}$ for women) [4].

Many theories for the pathophysiology of migraine have been proposed. According to a neurovascular theory, migraine headaches demonstrate vascular changes in secondary neuronal activation. As a result of neuronal events, blood vessels in pain-sensitive structures expand and lead to more trigeminal nerve activation and pain [2]. The exact pathology of migraine has yet to be fully understood. In 1 novel study, it was proposed that cytokines and some neuropeptides may have an important role in the pathogenesis of migraine [5]. Recent research has focused on the association between mi-

Address for correspondence: Turan Akdag, MD. Department of Plant and Animal Production, Meram Vocational School, Necmettin Erbakan University, Konya, Turkey

Phone: +90 5056597350 E-mail: turanakdag570@gmail.com ORCID: 0000-0003-3175-6751

Submitted Date: December 24, 2019 Accepted Date: March 03, 2020 Available Online Date: April 20, 2020

${ }^{\circ}$ Copyright 2020 by International Journal of Medical Biochemistry - Available online at www.internationalbiochemistry.com OPEN ACCESS This work is licensed under a Creative Commons Attribution-NonCommercial 4.0 International License. 
graine and neuropeptides. One of the newly identified peptide hormones, irisin, is composed of 112 amino acids and weighs $\sim 12 \mathrm{kDa}[6,7]$. It should be noted that irisin affects autocrine, paracrine, and endocrine hormones. Several studies have found that irisin can be identified in the skeletal muscles, adipose tissue, kidneys, neural cells, ovaries, myocardial and smooth muscles, endothelium, liver, and pancreas [8, 9]. Also, recent observations have demonstrated that irisin has been detected at high levels in the brain, including the Purkinje cells of the cerebellum. Although the hormone irisin is mainly synthesized from muscle tissue, studies have shown the presence of irisin in the neuronal areas of rats $[9,10]$. The physiological and hormonal effects of irisin still remain incompletely explained.

Nesfatin-1 has a molecular weight of $9.7 \mathrm{kDa}$ and is composed of 82 amino acids [11]. This newly discovered neuropeptide has antioxidant and antiapoptotic properties and plays a significant role in neurodegenerative damage and cerebrovascular events [12]. Nesfatin-1 has been found to be expressed mostly in the limbic system, the cortical nuclei, the dorsal motor nucleus of the vagus nerve, and the preganglionic sympathetic and parasympathetic neurons of the spinal cord [13]. One study concluded that nesfatin-1 plays a role in emotional and psychological events, such as panic disorder and chronic stress [14]. The present study is a preliminary assessment to determine serum irisin and nesfatin-1 levels in migraine without aura patients and examine whether these data could help with the identification or evaluation of the disease.

\section{Materials and Methods}

Eighty participants were included into the study in 2 groups: Migraine without aura patients (10 men, 30 women) and healthy subjects ( 10 men, 30 women). All of the participants were categorized in 10-year age groups from 20 to 59 years. The patients and healthy subjects had no metabolic diseases before the study. The exclusion criteria included any known history of headache disorder, endocrinopathy, cardiovascular disease, psychiatric disorder, cerebrovascular disease, neurological disorder, and the use of anti-inflammatory or steroid drugs, or anti-hypertensive medication. The patient data were obtained through self-reported questionnaires. The group of healthy controls was composed of participants with no migraine or headache complaints. Migraine without aura is the most frequent form of primary headache. Migraine without aura patients who were between migraine episodes were selected from individuals admitted to the neurology department of Konya Education and Research Hospital between March and December 2018. The migraine patients were diagnosed by an experienced neurologist according to the diagnostic criteria of the International Headache Society (IHS) (3rd edition, beta version).

According to the IHS, the diagnostic criteria of migraine without aura are at least 5 headache attacks lasting 4-72 hours with/without treatment and at least 2 of the following a) pulsating quality, b) unilateral or bilateral location, c) pain intensity that is moderate to severe, and d) increased pain with physical activity (daily routine activity), as well as the experience of either vomiting and/or nausea, or phonophobia or photophobia during the headache. A visual analog scale (VAS) was used to assess pain intensity in the migraine without aura patients with a rating from 0 (no pain) to 10 (worst pain). Body mass index (BMI) was calculated as weight $(\mathrm{kg})$ divided by the square of the height $\left(\mathrm{m}^{2}\right)$ according to the WHO BMI classification (Technical Report Series 854). The duration of migraine without aura was determined by a single neurologist based on the patient questionnaires and clinical examination. Blood samples $(10 \mathrm{~mL})$ drawn from each patient were transferred to biochemistry tubes in order to evaluate the serum nesfatin-1 and irisin levels. The samples were separated after coagulation, centrifuged at $3000 \mathrm{rpm}$ for 10 minutes, and stored in deep freeze at $-800 \mathrm{C}$ until the run time. The serum levels of irisin and nesfatin-1 were measured using enzyme-linked immunosorbent assay (ELISA) kits.

This study was approved by the ethics board of the Meram Faculty of Medicine of Necmettin Erbakan University in Konya, Turkey (approval number: 2018/1337-68) and conducted based on the principles of the Declaration of Helsinki. Written, informed consent was obtained from each participant prior to the study.

\section{Measurement of serum irisin and nesfatin-1}

Serum irisin levels were measured using ELISA kits (Human Irisin ELISA Kit, catalog no: 201-12-5328; Shanghai Sunred Biological Technology, Shanghai, China). The analytical sensitivity, assay range, and intra-assay and inter-assay variation rates were $0.157 \mathrm{ng} / \mathrm{mL}, 0.2-60 \mathrm{ng} / \mathrm{mL},<10 \%$, and $<12 \%$, respectively. Serum nesfatin-1 levels were also measured using ELISA kits (Human NES 1 ELISA Kit, catalog no: 201-12-4341; Shanghai Sunred Biological Technology, Shanghai, China). The analytical sensitivity was $0.113 \mathrm{mmol} / \mathrm{L}$, the assay range was $0.2-35 \mathrm{mmol} / \mathrm{L}$, the intra-assay variation was $<10 \%$, and the inter-assay variation was $<12 \%$. The kit manufacturer's instructions were followed throughout all of the analyses. The absorbance of the samples was measured at $450 \mathrm{~nm}$ and recorded using a microplate reader (ELx800; BioTek Instruments, Winooski, VT, USA).

\section{Statistical analysis}

The statistical analyses were performed using IBM SPSS Statistics for Windows, Version 22.0 (IBM Corp., Armonk, NY, USA). Differences between the migraine without aura patients and the healthy controls were evaluated with the Mann-Whitney $U$ test. The data were expressed as mean $\pm S D(X \pm S D)$. One-way analysis of variance and the Kruskal-Wallis tests were used for age categories, VAS and BMI scores, and disease duration. The results were accepted as statistically significant at $p<0.05$. 


\section{Results}

A total of 80 participants were recruited according to the exclusion criteria. As shown in Table 1, the mean serum level of irisin was $16.87 \pm 14.66 \mathrm{ng} / \mathrm{mL}$ in the migraine without aura group and $17.33 \pm 17.18 \mathrm{ng} / \mathrm{mL}$ in the healthy group. No significant $p$ values were determined $(p=0.470)$, but the irisin level was lower in the migraine group. The mean level of nesfatin-1 was $4.71 \mathrm{mmol} / \mathrm{L}$ in the migraine group and $4.13 \mathrm{mmol} / \mathrm{L}$ in the healthy group. While no significant $p$ values were determined ( $p=0.191$ ), the nesfatin- 1 level was slightly higher when compared with the healthy subjects. The BMI scores were not statistically significant $(p=0.136)$ (Table 1 ).
As seen in Table 2, no significant difference in the mean level of nesfatin-1 or irisin was found between the age groups of migraine patients [nesfatin- $1(p=0.070)$ and irisin $(p=0.146)$ ] and healthy group nesfatin- $1(p=0.424)$ and irisin $(p=0.248)$.

The study results also revealed no statistically significant difference in the serum irisin and nesfatin-1 level in terms of the VAS score or disease duration in the migraine without aura group $(p=0.388, p=0.312, p=0.555$, and $p=0.383$, respectively) (Table 3$)$.

\section{Discussion}

Migraine is a serious health problem affecting QoL in more than $10 \%$ of the general population [15]. Defined as a neo-

\section{Table 1. Comparison of nesfatin-1 and irisin levels in MWA and healthy groups}

\begin{tabular}{|c|c|c|c|}
\hline Parameters & MWA group & Healthy group & $\mathbf{p}$ \\
\hline Age (years, mean) & 36.74 & 37.82 & 0.56 \\
\hline \multirow[t]{2}{*}{ Sex (number) } & Men, $10(\% 25)$ & Men, $10(\% 25)$ & - \\
\hline & Women, 30 (\%75) & Women, 30 (\%75) & \\
\hline \multirow[t]{3}{*}{ Serum irisin (ng/mL) } & Mean: 16.87 & Mean: 17.33 & 0.470 \\
\hline & $\mathrm{n}: 40$ & $\mathrm{n}: 40$ & \\
\hline & SD: 14.66 & SD: 17.18 & \\
\hline \multirow[t]{3}{*}{ Serum nesfatin-1 (mmol/L) } & Mean: 4.71 & Mean: 4.13 & 0.191 \\
\hline & $\mathrm{n}: 40$ & $\mathrm{n}: 40$ & \\
\hline & SD: 5.96 & SD: 5.41 & \\
\hline $\mathrm{BMI},\left(\mathrm{kg} / \mathrm{m}^{2}\right)$ & $20.91 \pm 0.66$ & $22.14 \pm 0.93$ & 0.139 \\
\hline
\end{tabular}

BMI: Body mass index; MWA: Migraine without aura; SD: Standard devision.

Table 2. Comparison of nesfatin-1 and irisin levels according to age categories

\begin{tabular}{|c|c|c|c|c|}
\hline Age categories (years) & \multicolumn{2}{|c|}{ MWA group } & \multicolumn{2}{|c|}{ Healthy group } \\
\hline \multicolumn{5}{|l|}{$20-29$} \\
\hline Mean & 7.48 & 21.84 & 24.39 & 16.24 \\
\hline $\mathrm{n}$ & 9 & 9 & 8 & 8 \\
\hline SD & 7.21 & 14.74 & 33.05 & 14.92 \\
\hline Mean & 1.68 & 9.89 & 30.19 & 20.20 \\
\hline $\mathrm{n}$ & 15 & 15 & 12 & 12 \\
\hline SD & 1.23 & 9.59 & 32.64 & 13.83 \\
\hline \multicolumn{5}{|l|}{$40-49$} \\
\hline Mean & 7.22 & 23.92 & 18.45 & 18.18 \\
\hline $\mathrm{n}$ & 5 & 5 & 7 & 7 \\
\hline SD & 4.01 & 17.22 & 33.06 & 15.96 \\
\hline $\mathrm{p}$ & 0.070 & 0.146 & 0.424 & 0.248 \\
\hline
\end{tabular}

MWA: Migraine without aura; SD: Standard devision. 


\begin{tabular}{|c|c|c|c|}
\hline VAS scores & Values & df & $\mathbf{p}$ \\
\hline Nesfatin & 156.333 & 152 & 0.388 \\
\hline Irisin & 160.000 & 152 & 0.312 \\
\hline \multicolumn{4}{|c|}{ Duration of MWA } \\
\hline Nesfatin & 413.333 & 418 & 0.555 \\
\hline Irisin & 426.000 & 418 & 0.383 \\
\hline Number & 40 & & \\
\hline
\end{tabular}

MWA: Migraine without aura; VAS: Visual analog scale.

vascular disorder, migraine may be associated with different combinations of primary episodic headache disorders [16]. The exact component causing pain in migraine still remains unclear. The majority of migraine sufferers have migraine pain without aura. Clinically, migraine is commonly associated with transient neurological deficits, such as sensitivity to light or sound, throbbing, and vomiting [3].

Recent studies have proposed that adipo-myokines and some peptides may be linked to the pathogenesis of migraine. Lukacs et al. [5] reported that substance $P$, nitric oxide, vasoactive intestinal peptide, pituitary adenylate cyclase-activating polypeptide, and calcitonin gene-related peptide have potentially important roles in the regulation of inflammatory mechanisms in patients with migraine. Boström et al. [6] identified a new peptide, irisin, a member of the myokine family. This protein is a cleaved version of fibronectin type-III domaincontaining protein 5 (FNDC5), a member of the group of fibronectin type-III repeat containing genes modulated by peroxisome proliferator-activated receptor gamma coactivator 1 alpha [17]. Expressed FNDC5/irisin has been found not only in skeletal muscle muscles, but also in various regions of brain tissue [18]. New studies have shown the presence of FNDC5/ irisin protein in the hypothalamus, cerebellum, and spinal cord [19]. Similarly, immunoreactivity of FNDC5/irisin has been observed in neurons, astrocytes, and microglia in brain tissue [20]. The serum level of irisin is regulated by several factors, such as obesity, exercise, diet, pharmacologicals, and some pathological conditions [21]. Irisin was initially defined as a myokine protein [6], but new investigations have revealed that irisin acts as an adipokine [22], as well as a potential neurokine [23]. It is well documented that irisin plays a notable role in apoptosis and inflammatory and oxidative stress [24]. In a study performed by Bosma et al. [25] it was observed that in mice, FNDC4 (homology with FNDC5) may have an anti-inflammatory influence on macrophages and thus may improve colitis. However, the physiological properties and functional role of irisin in the brain have yet to be fully explained. New studies have noted that the level of irisin may be increased or decreased in many diseases. A study conducted by Ebert et al. [26] reported that the level of serum irisin was lower in chronic kidney disease. Similarly, the serum irisin levels were lower in patients with type 2 diabetes mellitus (DM) [27]. A recent study has shown that a low level of serum irisin was a possible biomarker in the early prediction of ischemic stroke [28]. Ates et al. [29] demonstrated that the level of irisin was higher in patients with type $1 \mathrm{DM}$. Our study revealed a minimal decrease in the serum irisin levels in migraine patients compared with the healthy group, although the difference was statistically insignificant $(p=0.470)$. In a previous study, the mean serum irisin level of a healthy group was determined to be $3.6 \mathrm{ng} / \mathrm{mL}$ [30]. In contrast, the mean serum level of irisin was $17.33 \mathrm{ng} / \mathrm{mL}$ in the healthy subjects in our study. New studies have suggested that irisin may have a therapeutic use for some diseases. In a study performed in mice, oral irisin was demonstrated to have a protective effect in the treatment of atherosclerosis [31]. Further studies are needed to clarify this issue.

Several studies have focused on the physiology of nesfatin-1 and its role in different diseases. It has been reported that chronic stress may elevate the plasma levels of nesfatin-1 [32]. Ari et al. [33] concluded that plasma nesfatin-1 levels were increased in patients with major depressive disorder. Several studies have shown that migraine was associated with oxidative mechanisms and affected by oxidative factors [34, 35]. Also, it has been observed that nesfatin-1 had a significant effect on the suppression of brain damage resulting from oxidative mechanisms [12]. Aydın et al. [36] revealed that serum and saliva levels of nesfatin-1 were remarkably higher in patients with epilepsy than those of controls. The human serum and saliva nesfatin-1 levels $(25.8 \pm 5.84 \mathrm{ng} / \mathrm{mL}, 33.5 \pm 8.79 \mathrm{ng} /$ $\mathrm{mL}$, respectively) in untreated epileptic patients were 160 times greater than those of control subjects $(0.16 \pm 0.002 \mathrm{ng} /$ $\mathrm{mL}, 0.21 \pm 0.003 \mathrm{ng} / \mathrm{mL}$, respectively). Interestingly, another study determined that the level of nesfatin-1 was higher in patients with schizophrenia compared with a control group (10.51-350.8 pg/mL, 4.86-68.91 pg/mL, respectively) [37]. In our study, a slight increase in the serum level of nesfatin- 1 was observed in patients with migraine without aura compared with the healthy group; however, the difference was not statistically significant $(p=0.19)$ (Table 1). Xiao et al. [38] determined a level of nesfatin- 1 of $5.33 \mathrm{mmol} / \mathrm{L}$ in the healthy group, which is similar to the findings observed in our study $(5.41 \mathrm{mmol} / \mathrm{L})$.

Distress and disturbances caused by the disruptive symptoms of migraine represent one of the most important problems for patients with migraine and result in elevated social and fiscal burdens on both the individual and national health systems. Currently, only a limited number of biochemical parameters are utilized in the diagnostic process of migraine. The availability of rapid and sensitive biomarkers is important for early diagnosis, prognosis, and treatment of migraine.

\section{Conclusion}

To the best of our knowledge, this is the first study to examine the serum levels of irisin and nesfatin- 1 in patients with migraine without aura. We performed the analysis according to the ELISA kit manufacturer's instructions and methods. Nonetheless, there are limitations to the present research. We 
did not use a control serum and the present study was performed in only a single province. Therefore, more comprehensive multi-centered research and studies with larger populations are needed to further understand the entity of migraine without aura.

Acknowledgements: We would like to thank all of the study participants as well as the staff of Necmettin Erbakan University and the neurology department of Konya Education and Research Hospital. The authors also thank Numan Duran for assistance with language editing.

\section{Conflict of interest: No conflicts of interest.}

Ethics Committee Approval: This study was approved by the ethics board of the Meram Faculty of Medicine of Necmettin Erbakan University in Konya, Turkey (Approval number: 2018/133768).

Financial Disclosure: The study was supported by the research fund of Necmettin Erbakan University in Konya, Turkey (project number: 181235002).

Peer-review: Externally peer-reviewed.

Authorship contributions: Concept - T.A., F.Ö.O.; Design - T.A., F.Ö.O.; Supervision - F.Ö.O.; Funding - T.A., F.Ö.O.; Materials F.Ö.O.; Data collection \&/or processing - T.A., F.Ö.O.; Analysis and/ or interpretation - T.A.; Literature search - T.A., F.Ö.O.; Writing T.A., F.Ö.O.; Critical review - T.A., F.Ö.O.

\section{References}

1. Malhotra R. Understanding migraine: Potential role of neurogenic inflammation. Ann Indian Acad Neurol 2016;19(2):17582. [CrossRef]

2. Burstein R, Noseda R, Borsook D. Migraine: multiple processes, complex pathophysiology. J Neurosci 2015;35(17):6619-29.

3. Ahmed F, Parthasarathy R, Khalil M. Chronic daily headaches. Ann Indian Acad Neurol 2012;15(Suppl 1):S40-S50. [CrossRef]

4. Headache Classification Committee of the International Headache Society (IHS). The International Classification of Headache Disorders, 3rd edition (beta version). Cephalalgia 2013;33(9):629-808. [CrossRef]

5. Lukacs M, Tajti J, Fulop F, Toldi J, Edvinsson L, Vecsei L. Migraine, Neurogenic Inflammation, Drug Development - Pharmacochemical Aspects. Curr Med Chem 2017;24(33):3649-65.

6. Boström P, Wu J, Jedrychowski MP, Korde A, Ye L, Lo JC, et al. A PGC1-a-dependent myokine that drives brown-fatlike development of white fat and thermogenesis. Nature 2012;481(7382):463-8. [CrossRef]

7. Schumacher MA, Chinnam N, Ohashi T, Shah RS, Erickson HP. The structure of irisin reveals a novel intersubunit $\beta$-sheet fibronectin type III (FNIII) dimer: implications for receptor activation. J Biol Chem 2013;288(47):33738-44. [CrossRef]

8. Aydin S, Kuloglu T, Aydin S, Kalayci M, Yilmaz M, Cakmak T, et al. A comprehensive immunohistochemical examination of the distribution of the fat-burning protein irisin in biological tissues. Peptides 2014;61:130-6. [CrossRef]

9. Hashemi MS, Ghaedi K, Salamian A, Karbalaie K, Emadi-Baygi $M$, Tanhaei $S$, et al. Fndc5 knockdown significantly decreased neural differentiation rate of mouse embryonic stem cells. Neuroscience 2013;231:296-304. [CrossRef]

10. Hofmann T, Elbelt U, Stengel A. Irisin as a muscle-derived hormone stimulating thermogenesis--a critical update. Peptides 2014;54:89-100. [CrossRef]

11. Oh-I S, Shimizu H, Satoh T, Okada S, Adachi S, Inoue K, et al. Identification of nesfatin-1 as a satiety molecule in the hypothalamus. Nature 2006;443(7112):709-12. [CrossRef]

12. Özsavcí D, Erşahin $M$, Şener A, Özakpinar ÖB, Toklu HZ, Akakín $D$, et al. The novel function of nesfatin-1 as an anti-inflammatory and antiapoptotic peptide in subarachnoid hemorrhage-induced oxidative brain damage in rats. Neurosurgery 2011;68(6):1699-708. [CrossRef]

13. Kohno D, Nakata M, Maejima Y, Shimizu H, Sedbazar U, Yoshida $\mathrm{N}$, et al. Nesfatin-1 neurons in paraventricular and supraoptic nuclei of the rat hypothalamus coexpress oxytocin and vasopressin and are activated by refeeding. Endocrinology 2008;149(3):1295-301. [CrossRef]

14. Bez Y, Ari M, Ozturk OH, Oktar S, Can Y, Sogut S. Plazma Nesfatin-1 Level May Be Associated with Disease Severity in Patients with Panic Disorder. Clin Psychopharmacol 2010;20:28892. [CrossRef]

15. Rasmussen BK, Jensen R, Schroll M, Olesen J. Epidemiology of headache in a general population--a prevalence study. J Clin Epidemiol 1991;44(11):1147-57. [CrossRef]

16. Zheng Z, Xiao Z, Shi X, Ding M, DiW, Qi W, et al. White matter lesions in chronic migraine with medication overuse headache: a cross-sectional MRI study. J Neurol 2014;261(4):784-90.

17. Erickson HP. Irisin and FNDC5 in retrospect: An exercise hormone or a transmembrane receptor?. Adipocyte 2013;2(4):289-93. [CrossRef]

18. Aydin S, Aydin S, Kuloglu T, Yilmaz M, Kalayci M, Sahin I, et al. Alterations of irisin concentrations in saliva and serum of obese and normal-weight subjects, before and after $45 \mathrm{~min}$ of a Turkish bath or running. Peptides 2013;50:13-8. [CrossRef]

19. Zhang J, Zhang W. Can irisin be a linker between physical activity and brain function?. Biomol Concepts 2016;7(4):253-8.

20. Albayrak S, Atci IB, Kalayci M, Yilmaz M, Kuloglu T, Aydin S, et al. Effect of carnosine, methylprednisolone and their combined application on irisin levels in the plasma and brain of rats with acute spinal cord injury. Neuropeptides 2015;52:47-54.

21. Mahgoub MO, D'Souza C, Al Darmaki RSMH, Baniyas MMYH, Adeghate $\mathrm{E}$. An update on the role of irisin in the regulation of endocrine and metabolic functions. Peptides 2018;104:15-23.

22. Roca-Rivada A, Castelao C, Senin LL, Landrove MO, Baltar J, Belén Crujeiras A, Seoane LM, Casanueva FF, Pardo M. FNDC5/ irisin is not only a myokine but also an adipokine. PLoS One 2013;8(4):e60563. [CrossRef]

23. Ruan Q, Zhang L, Ruan J, Zhang X, Chen J, Ma C, Yu Z. Detection and quantitation of irisin in human cerebrospinal fluid by tandem mass spectrometry. Peptides 2018;103:60-4. 
24. Zhu D, Wang H, Zhang J, Zhang X, Xin C, Zhang F, et al. Irisin improves endothelial function in type 2 diabetes through reducing oxidative/nitrative stresses. J Mol Cell Cardiol 2015;87:138-47. [CrossRef]

25. Bosma M, Gerling M, Pasto J, Georgiadi A, Graham E, Shilkova $O$, et al. FNDC4 acts as an anti-inflammatory factor on macrophages and improves colitis in mice. Nat Commun 2016;7:11314. [CrossRef]

26. Ebert T, Focke D, Petroff D, Wurst U, Richter J, Bachmann A, et al. Serum levels of the myokine irisin in relation to metabolic and renal function. Eur J Endocrinol 2014;170(4):501-6. [CrossRef]

27. Choi YK, Kim MK, Bae KH, Seo HA, Jeong JY, Lee WK, et al. Serum irisin levels in new-onset type 2 diabetes. Diabetes Res Clin Pract 2013;100(1):96-101. [CrossRef]

28. Wu H, Guo P, Jin Z, Li X, Yang X, Tang C, et al. Serum levels of irisin predict short-term outcomes in ischemic stroke. Cytokine 2019;122:154303. [CrossRef]

29. Ates I, Arikan MF, Erdogan K, Kaplan M, Yuksel M, Topcuoglu C, et al. Factors associated with increased irisin levels in the type 1 diabetes mellitus. Endocr Regul 2017;51(1):1-7. [CrossRef]

30. Jedrychowski MP, Wrann CD, Paulo JA, Gerber KK, Szpyt J, Robinson MM, et al. Detection and Quantitation of Circulating Human Irisin by Tandem Mass Spectrometry. Cell Metab 2015;22(4):734-40. [CrossRef]
31.Zhang Y, Mu Q, Zhou Z, Song H, Zhang Y, Wu F, et al. Protective Effect of Irisin on Atherosclerosis via Suppressing Oxidized Low Density Lipoprotein Induced Vascular Inflammation and Endothelial Dysfunction. PLoS One 2016;11(6):e0158038.

32. Ayada C, Toru Ü, Korkut Y. Nesfatin-1 and its effects on different systems. Hippokratia 2015;19(1):4-10.

33. Ari M, Ozturk OH, Bez Y, Oktar S, Erduran D. High plasma nesfatin-1 level in patients with major depressive disorder. Prog Neuropsychopharmacol Biol Psychiatry 2011;35(2):497-500.

34. Kowalska M, Prendecki M, Kozubski W, Lianeri M, Dorszewska J. Molecular factors in migraine. Oncotarget 2016;7(31):50708-18.

35. Borkum JM. The Migraine Attack as a Homeostatic, Neuroprotective Response to Brain Oxidative Stress: Preliminary Evidence for a Theory. Headache 2018;58(1):118-35. [CrossRef]

36. Aydin S, Dag E, Ozkan Y, Erman F, Dagli AF, Kilic N, et al. Nesfatin-1 and ghrelin levels in serum and saliva of epileptic patients: hormonal changes can have a major effect on seizure disorders. Mol Cell Biochem 2009;328(1-2):49-56. [CrossRef]

37. Ünal K, Yüksel RN, Turhan T, Sezer S, Yaylaci ET. The association of serum nesfatin- 1 and ghrelin levels with metabolic syndrome in patients with schizophrenia. Psychiatry Res 2018;261:45-9.

38. Xiao MM, Li JB, Jiang LL, Shao H, Wang BL. Plasma nesfatin-1 level is associated with severity of depression in Chinese depressive patients. BMC Psychiatry 2018;18(1):88. [CrossRef] 